\title{
PROFESSIONAL PSYCHOLOGICAL STRESS MANAGEMENT IN CHRONIC RENAL FAILURE PATIENTS
}

\author{
Svetla Staykova, Rositsa Dimitrova-Zlatkova \\ Clinic of Dialysis, Department of Internal Medicine, \\ Medical University of Varna
}

\begin{abstract}
PURPOSE: Any patients with chronic diseases, and especially those with chronic renal failure, face not only the specific physical aspects of their own primary pathology but also the psychological distress when realizing the severity of the progression of this disease and its poor prognosis. The objective of this study was to reveal some psychological features of the patients on haemodialysis.

MATERIAL AND METHODS: The investigation covered 70 patients, 43 males and 27 females with chronic renal failure treated in the Clinic of Dialysis of Varna and in the Dialysis Centre of Targovishte. The patients filled in anonymous questionnaires and underwent a psychological examination according to a modified anxiety scale.

RESULTS: Recently, the number of emergency cases in both haemodialysis centres increased. In Varna, the emergency cases were 34 out of 37 while in Targovishte, these amounted to 8 out of 11 . This hampered the provision of sufficient information about the disease to the patients. At the onset of treatment, social activity was preserved in $44 \%$ of the patients while after 12 months this persisted in $16 \%$ of them. More than $85 \%$ of the patients retired due to disability caused by the renal disease. The influence on the interpersonal relations of the disease-related stress and anxiety was very unfavourable.

CONCLUSION: There is a necessity to apply individualized psychotherapeutic approach to the patients with chronic renal failure in order to improve their adjustment to this severe pathology and collaboration with the physician as well as to minimize their feeling of inevitability.
\end{abstract}

Key words: chronic renal failure, hemodialysis, stress, anxiety, questionnaire

\section{INTRODUCTION}

Haemodialysis is widely used in the patients with chronic renal failure (CRF). Recently, an emphasis is made not only on the improvement of the

Address for correspondence:

Svetla Staykova, $M D, P h D$

Clinic of Dialysis, Department of Internal Medicine,

Medical University of Varna

55 Marin Drinov Str., 9002 Varna, Bulgaria

Mobile: +359-0885841663

E-mail:svetlastaykova@abv.bg

Received: August 30, 2012

Accepted: January 15, 2013 methods of extracorporeal technological substitution of damaged or even lost organ functions but also on the professio0nal psychological management of accompanying stress and anxiety due to the disease.

The stress model introduces the social aspect as a bridge between the psychological and somatic functions and this way integrates the etiopathogenic factors. It is suggested that stress causes physiological dysfunctions through psychological mechanisms.

The psychological hypertension and injuries exert a powerful influence on the already existing disease. This stands out mainly in the patients with chronic diseases and with CRF in particular. They are traumatised not only by the physical suffering due to the specificity of the primary disease but also 
by the psychological shock they experience when becoming aware of its severe prognosis $(1,2,5)$.

The duration of dialysis treatment, the additional psychological shock by the fact that the patient is dependent on the apparatus and the specific hospital regime limiting his personal freedom and independence create a lot of stress situations.

The aim of the present study is to determine if CRF patients on haemodialysis live under numerous psychological stress situations and if their families need psychological support and advice, too, in order to adapt and deal with these new problems derived from the main disease of their family member.

\section{MATERIAL AND METHODS}

The study covered 50 patients, 30 males and 20 females, aged between 17 and 70 years (mean age of 27 $\pm 6,2$ years) treatedt between one month and 12 years in the Clinic of Dialysis, St. Marina University Hospital of Varna, and 20 patients, 13 males and 7 females aged between 23 and 65 years, mean age of $46 \pm 6,2$ years treated in Dialysis Centre of Targovishte, Bulgaria. All the patients were on haemodialysis for 10-12 hours per week using bicarbonated dialisis solution.

The patients filled in anonymous questionnaires and underwent a clinical observation and a psychological examination according to an anxiety scale a modified from MMPI by T. A. Nemchin.

\section{RESULTS}

Our results show that because of the high percentage of emergency cases and the lack of possibility for sufficient individual attention paid to the patients the amount of information given and received in the Dialysis Centre of Targovishte is greater than that in the Clinic of Dialysis of Varna. During the last 3 months, , the emergency cases were 34 out of 37 in Varna but 8 out of 11 in Targovishte.

Our results are presented on Fig. 1 and Fig. 2.

The necessity of systematic and complex psychological care is determined in the beginning of the dialysis treatment and in the end of it. At the onset of haemodialysis, the social activity is preserved in

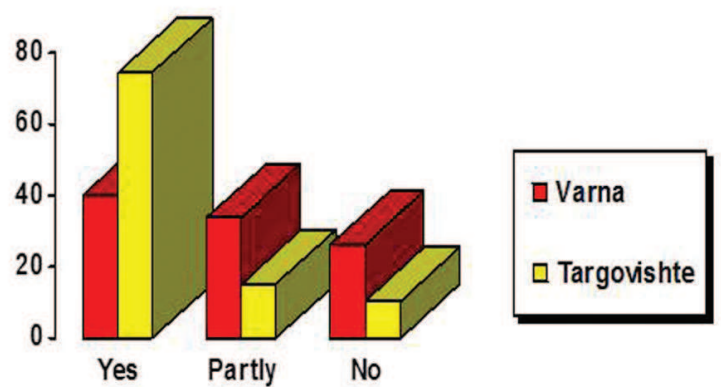

Fig. 1. Rate of patient's stress in Varna and in Targovishte

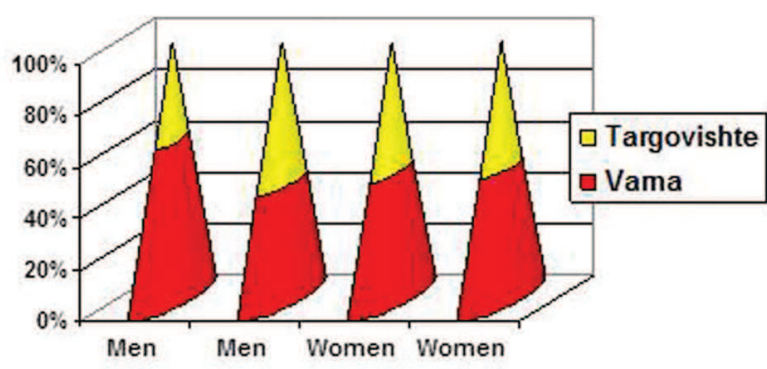

Fig. 2. Rate of patient's anxiety in Varna and in Targovishte

$44 \%$ of the patients and after 12 month treatment, it does in $16 \%$ only. The rate of anxiety is higher in men than in women. This difference stands no matter of the duration of the treatment. The rate is almost the same in the both centres. Patient's anxiety presents with fear, distrust and lack of confidence.

More than $85 \%$ of the patients on periodic haemodialysis have retired due to disability caused by the renal disease. Treatment duration reflects on mentality not only of the patients themselves but also of their family or life partners. Some investigations dealing with relatives' psychological reactions demonstrate that exploring the difficulties in the family relationships and their overcoming must occupy an important place in the system of the complex therapeutic approach to the patient.

\section{DISCUSSION}

Two methods of work could be offered:

i) medicinal affecting some pathological units, and ii) influence by psychosocial interventions which are necessary in a long-time treatment and aim at 
overcoming the large number of critical conditions experienced by the patients.

These pathways of influence, i. e. somatic, psychological and socio-therapeutic must be used together. The best results are obtained using a team of psychologists, physicians and social workers. The problems of CRF patients could be solved by this way only $(3,4,6,7)$.

The following important tasks are faced by the psychologist in a haemodialysis centre:

1. Evaluation of the psychologic problem associated with the disease.

2. Evaluation of patient's psychologic potential.

3. Formulation of the disease in the language of the personal suffering.

4. Creation of conditions in the clinical sector allowing the patients and their relatives to discuss and consult their psychological status.

\section{CONCLUSION}

The present investigation demonstrates that CRF patients are under the conditions of permanent stress resulting from their severe renal disease and improve patient's adjustment to the disease, try to restore the psychological balance, allow cooperation with the physician and thus minimize the feeling of inevitability.

\section{REFERENCES}

1. Ivanov, V. Practical psychosomatic medicine. Stara Zagora, Znanie, 1999 (in Bulgarian).

2. Ivanov, I. Functional condition study methods. Shumen, 1999 (in Bulgarian).

3. Kambova, L. Why is psychologic care necessary in haemodialysis centres?- Psychosom. med., 5, 1997, No 1, 68-71 (in Bulgarian).

4. Kokoshkarova, D. Psychological personality study in clinical practice. Sofia, Meditsina i fizkultura, 1982 (in Bulgarian).

5. Peseschkian, N. Psychosomatics and positive psychotherapy. Varna, Slavena, 2003 (in Bulgarian).

6. Terziyski, R. Different models of stress, crises, diseases. Coping with disease.- Psychosom. med., 6, 1998, No 1-2, $45-47$ (in Bulgarian).

7. Levi, N. Psychology and rehabilitation.- In: Handbook of dialysis. Boston and Toronto, Little Brown and Co., 1988, 279-283. 